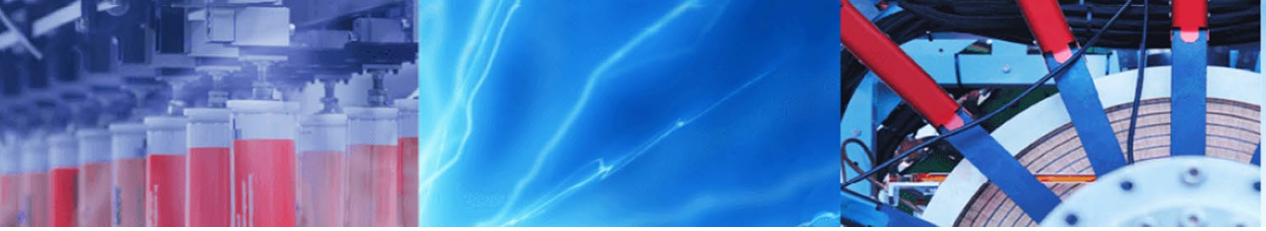

Research Article

\title{
Determination of melatonin content of different varieties of hemp (Cannabis sativa L.) by liquid chromatography tandem mass spectrometry
}

\author{
Gianna Allegrone ${ }^{1}$ (D) . Federica Razzano ${ }^{1} \cdot$ Federica Pollastro $^{1} \cdot$ Gianpaolo Grassi $^{2}$
}

(c) Springer Nature Switzerland AG 2019

\begin{abstract}
Melatonin ( $\mathrm{N}$-acetyl-5-methoxytryptamine), was first isolated in the bovine pineal gland, and then was discovered in bacteria, algae and higher plants. Melatonin concentrations in plants differ from species to species, among varieties within the same species and also within different organs or tissues of a given plant as roots, leaves, fruits, flowers, and seeds. Although the presence of melatonin in plants seems to be a universal trait, there is still lack of information on its occurrence in several plants, in particular in hemp (Cannabis sativa L.). The aim of this study was to develop a method to quantitate melatonin in the aerial parts of the plant, constituted of leaves and flower heads, and in the seeds, of four different hemp varieties using liquid chromatography-tandem mass spectrometry (LC-ESI/MS/MS). A sample preparation procedure with methanol extraction followed by solid-phase clean-up protocol was set up for melatonin extraction and a LC-ESI/MS/MS method in single reaction monitoring (SRM) was used for its determination. Chromatographic separation was achieved on a C18 column using a gradient elution with acetonitrile-buffer ammonium formate/formic acid system. The developed method, validated as per International Conference on Harmonization guidelines, was successfully applied to analyze hemp samples varieties belonging to fiber-type or drug-type chemotypes. The melatonin was found to accumulate highly in seeds in the range $13.43-30.40 \mathrm{ng} \mathrm{g}^{-1}$ while the content in the aerial parts was assessed in the range 1.16-4.85 $\mathrm{ng} \mathrm{g}^{-1}$. No correlation was found between the melatonin levels detected in aerial parts and seeds in each hemp variety and the concentration of specific cannabinoids in the same variety.
\end{abstract}

Graphic abstract

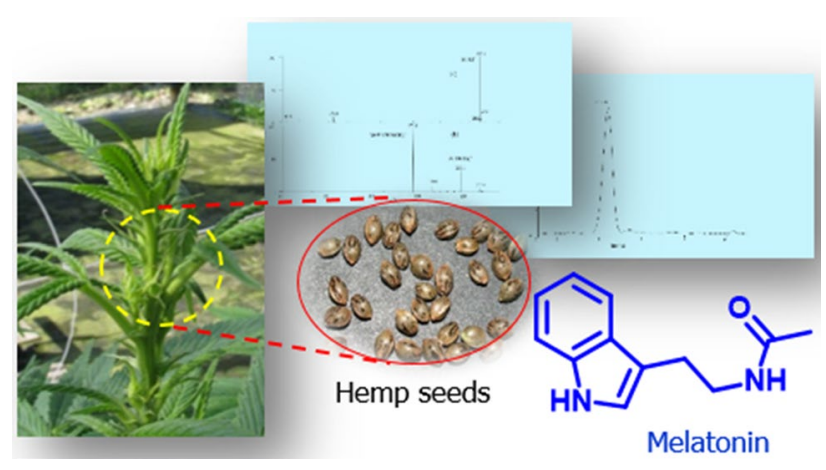

Keywords Melatonin · LC-MS/MS · Hemp · Cannabis sativa L.

\footnotetext{
$\triangle$ Gianna Allegrone, gianna.allegrone@uniupo.it | ${ }^{1}$ Dipartimento di Scienze del Farmaco, Università del Piemonte Orientale, Largo Donegani 2, 28100 Novara, Italy. ${ }^{2}$ Consiglio per la ricerca in agricoltura e l'analisi dell'economia agraria, Centro di Ricerca per le Colture Industriali, CREA-Cl, Viale G. Amendola 82, 45100 Rovigo, Italy.
}

SN Applied Sciences (2019) 1:720 | https://doi.org/10.1007/s42452-019-0759-y

Received: 12 October 2018 / Accepted: 11 June 2019 / Published online: 14 June 2019 


\section{Introduction}

Melatonin ( $\mathrm{N}$-acetyl-5-methoxytryptamine) (Fig. 1 ) is a hormone isolated and identified for the first time in the pineal gland of vertebrates and later found in many species, such as bacteria, fungi, plants [1] and different animal species, including humans. Melatonin biosynthesis in pineal gland cells was identified by Axelrod [2]: tryptophan acts as the precursor and is converted into 5 -hydroxytryptophan by the enzyme tryptophan hydroxylase (TPH); by means of the aromatic amino acid decarboxylase (AAAD) serotonin is next obtained and then converted by the arylalkylamine $\mathrm{N}$-acetyltransferase (AANAT) in $\mathrm{N}$-acetylserotonin, eventually converted into melatonin by $N$ acetylserotonin methyltransferase (ASMT). Once synthesized, melatonin is not stored in the pineal gland but secreted into blood capillaries and cerebrospinal fluids [3]. Also owing to its amphipathic nature, melatonin is able to permeate all tissues and subcellular compartments. The enzymes responsible for biosynthesis of melatonin are also present in human lymphocytes [1] in the retina, skin, bone marrow and, in large quantities, in the gastrointestinal tract. In human, pineal melatonin production has a circadian rhythm, with high production overnight and low levels during the day; as the years passed, the pineal gland is reduced in size and melatonin production decreases.

Melatonin plays a very important role as an antioxidant against free radicals production either directly or through the stimulation of antioxidant enzymes (promoting transcription) and by reducing the activity of those pro-oxidants [3]. This substance is involved in the regulation of the immune system [3-5] and in the glucose metabolism, as low levels of melatonin increase blood glucose levels

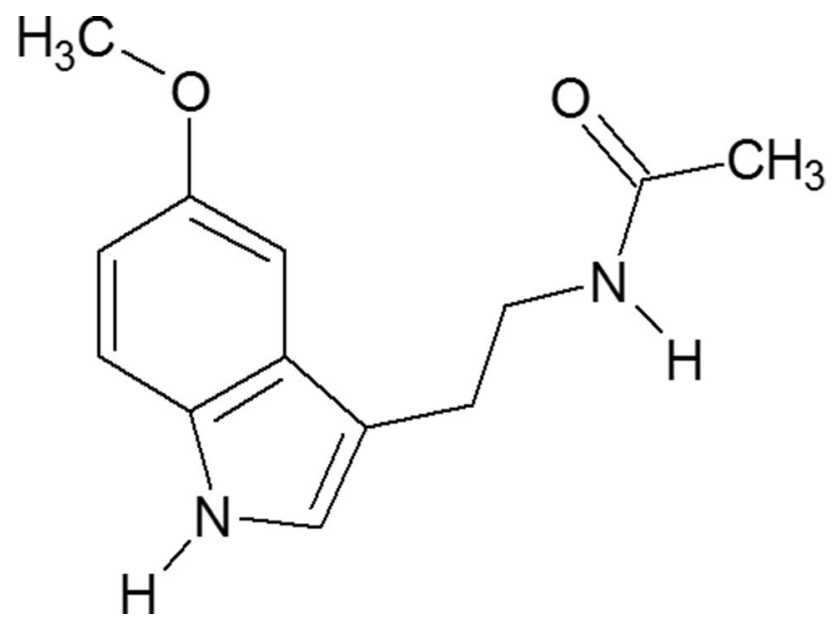

Fig. 1 Chemical structure of melatonin ( $N$-acetyl-5-methoxytryptamine)
$[4,6]$. It also acts as modulator of gastrointestinal motility $[4,7-9]$ and protector of fibroblasts and myelin $[10,11]$.

The first evidence that melatonin exists in plants came from two independent groups in 1995 [12, 13], and in subsequent years, melatonin was also detected in roots, leaves, fruits, flowers, and seeds of a variety of vegetables, cereals, fruits, as well in medicinal herbs $[14,15]$. The potent free-radical scavenger properties of melatonin and its broad-spectrum antioxidant activity in animals suggest that it acts similarly in plants [16].

The biosynthetic pathway of melatonin in plants is different from that in the pineal gland of vertebrates: tryptophan is converted to tryptamine by tryptophan decarboxylase, subsequently a hydroxylase converts into serotonin; the following steps en route to melatonin are the same that occur in mammals [17]. In plants, roots could be a potential site of melatonin biosynthesis but the generality of this view is unproven. Currently, no melatonin receptors or binding sites have been identified in plants; alternatively, since melatonin has similar structure to auxin, it could possibly interact with the auxin receptor [18]. Auxin is involved in modulating the development of roots and leaves, in the interactions between plant and pathogenic, and seems to protect against senescence. Melatonin might therefore agonistically mimic the properties of auxin, acting as a growth hormone. Melatonin can penetrate all intracellular compartments and protect all parts of the plant from oxidative stress and cell death, particularly germ and reproductive tissues [19, 20]. Melatonin can directly scavenge reactive oxygen species and stimulates the activity of antioxidant enzymes; it is also able to protect cells from lipid peroxidation and proteins and DNA from damage [21, 22]. It also acts as cell protector, modulator of cytoskeleton, growth promoter and protector against low and high temperatures as well as drought, and could also be involved in photosynthesis [19, 22].

From the first detection of melatonin in plant in 1995, numerous studies have shown the presence of melatonin in different plant species and tissues, with concentrations ranging from $\mathrm{pg} \mathrm{g}^{-1}$ to $\mu \mathrm{g} \mathrm{g}^{-1}$ of plant material [20,23-28]. Melatonin concentrations in the plants differ not only from species to species but also among varieties within the same species. Moreover, the melatonin levels also vary within different organs or tissues of a given plant, and the highest contents have generally been reported in reproductive organs such as flowers, fruits and the seeds [13, 14].

Although the presence of melatonin seems to be a common trait of many plants, there is still lack of information on its occurrence hemp (Cannabis sativa L.), herbaceous annual dioecious plant bearing male and female flowers on separate plants. The taxonomy of hemp has always been controversial, but there seems now a general 
consensus to view it as a single species, Cannabis sativa L., sorted out into several varieties or chemotypes. To date, more than 480 constituents have been identified from of Cannabis, out of which almost 150 are classified as cannabinoids, enclosed in glandular tricomes of unfertilized flower heads of the female plant [29]. However, many other natural product classes besides the cannabinoids been identified from aerial parts (flowers heads and leaves) of Cannabis sativa $\mathrm{L}$. including monoterpenes, sesquiterpenes, flavonoids, stilbenes, steroids, fatty acids, and nitrogenous compounds [30-33].

Different analytical techniques to detect melatonin in plants have been reported, including radioimmunoassay [12], immunoprecipitation [28], HPLC combined with fluorescence detection, elettrochemical detection or mass spectrometry $[19,25,26]$. Liquid chromatography-tandem mass spectrometry (LC-MS/MS) seems up to now the most reliable technique to determine melatonin in plants [34, 35]. However the complicated matrix of each selected plant and tissue extract and its low concentrations always require the set up of a specific extraction and purification procedure of endogenous melatonin prior the analysis.

The aim of this study was to develop a simple, reliable and validate analytical method for the extraction, purification and quantitation of melatonin in hemp (Cannabis sativa $L$.). The method was applied to investigate the amount of melatonin in different hemp varieties, belonging to fiber-type and drug-type chemotype. Inside each hemp variety, melatonin was determined in two organs, the aerial parts (flower heads and leaves) and the reproductive organ (seeds).

\section{Experimental}

\subsection{Materials and reagents}

All solvents and reagents were of analytical or the highest grade available. Acetonitrile (HPLC grade), methanol (HPLC grade), formic acid ( $98 \% \mathrm{w} / \mathrm{w}$ ) and sodium sulphate were purchased from Sigma-Aldrich (Milan, Italy). Water analytical grade was obtained by ultrafiltration with Elga PureLab Ultra, (M Medical, Cornaredo, MI, Italy).

Isolute SPE columns $\mathrm{C} 181 \mathrm{~g}, 6 \mathrm{~mL}$ (Biotage) were purchased from Step Bio (Bologna, Italy) and were used on a Waters extraction vacuum manifold (Waters, Milford, USA). Syringe filters (nylon $0.22 \mu \mathrm{m}$ ) were purchased from Waters (Milford, USA)

Analytical standard melatonin ( $\mathrm{N}$-acetyl-5-methoxytryptamine) (>98\% w/w) was supplied from Effegilab s.r.l. (Trento, Italy).

Standard stock solutions of melatonin $\left(1 \mathrm{mg} \mathrm{mL}^{-1}\right)$ were prepared in methanol and kept in refrigerator for no more than 1 month. Freshly intermediated stock solutions (100 $\mathrm{ng} \mathrm{mL}^{-1}$ ) were made by diluting properly the standard stock solution using methanol. All working standard solution were prepared daily prior to use.

\subsection{Plant materials}

Different varieties of Cannabis sativa L. belonging to fiber-type or drug-type chemotypes were obtained from outdoor cultivations at CREA-CIN (Rovigo, Italy). Most of them are registered at the CPVO (Community Plant Variety Office). The aerial parts (leaves and flower heads) of Ermes variety-CBD chemotype (Grant No. 16304), Carma variety-CBG chemotype (Grant No. 16305), Ermo varietyno cannabinoids chemotype (Grant No. 33448) and G170 strain THC chemotype varieties were harvested at their optimum maturity during 2013 year, Carma-CBG chemotype varietie was harvested also during year 2012. Seed of Ermes-CBD chemotype, Codimono-CBD chemotype, Carma-CBG chemotype, Ermo-no cannabinoids chemotype and G170-THC chemotypes varieties were collected in 2012. The CREA-CIN has received from the Ministry of Health's authorization to growth all Cannabis chemotypes. The license is no. 62237-SP192 of the 2012.

All samples were dried at $40{ }^{\circ} \mathrm{C}$ for 2 days and then grinded using a home type grinder prior to extraction.

\subsection{Sample preparation}

$3.0 \mathrm{~g}$ of dried and powdered aerial parts samples were extracted with $3 \times 30 \mathrm{~mL}$ methanol in three step under stirring for $1 \mathrm{~h}$ each. After filtration and washing of the plant residue, the pooled filtrates were evaporated to dryness under vacuum with rotavapor. The final residue was redissolved in $5 \mathrm{ml}$ of methanol and further purified according the solid-phase clean-up protocol set up for melatonin extraction. An aliquot of the extract reconstituted $(1 \mathrm{~mL})$ was introduced into a glass flask-tube and water/methanol $(9: 1, v / v 4 \mathrm{~mL})$ mixture was added. The sample mixture was loaded (flow rate $1 \mathrm{~mL} \mathrm{~min}{ }^{-1}$ ) onto the SPE column that has been previously conditioned with $5 \mathrm{~mL}$ of methanol and $5 \mathrm{~mL}$ of water. A clean up followed with $5 \mathrm{~mL}$ of water and $5 \mathrm{~mL}$ of water/methanol $(95: 5, \mathrm{v} / \mathrm{v})$ mixture. Column drying was performed under reduced pressure by vacuum application and $\mathrm{N}_{2}$ flow. Elution of the analytes was performed with acetonitrile ( $3 \mathrm{~mL})$; the extracts after drying on magnesium sulphate were evaporated under reduced pressure and the residues were reconstituted with $1 \mathrm{~mL}$ of methanol. Blank samples and melatonin standard solution of $5.0,10.0,100.0 \mathrm{ng} \mathrm{mL}^{-1}$ were treated in the same way onto SPE column procedure.

The seeds samples extraction was accomplished by the same procedure descripted for the aerial parts but, before 
the methanolic extraction, it was necessary defatted the seeds with a prior extraction with $30 \mathrm{~mL}$ of hexane under stirring for $30 \mathrm{~min}$.

\subsection{LC-MS/MS condition}

Chromatographic separation was performed using a Surveyor LC coupled with an LCQ DECA XP Plus (Thermo Finnigan, San Josè, USA) Ion Trap mass spectrometer. The LC system was equipped with binary capillary pump (Surveyor MS pump) and autosampler (Surveyor AS). Separations were performed on an analytical column Synergi Hydro $4 \mu \mathrm{m}$ C18 reverse phase, $150 \mathrm{~mm} \times 2.0 \mathrm{~mm}$ (Phenomenex, Torrance, CA) protected with a C18 Security Guard cartridge, $4 \mathrm{~mm} \times 2.0 \mathrm{~mm}$ (Phenomenex) and maintained at $37^{\circ} \mathrm{C}$. The injection volume was $5 \mu \mathrm{L}$. The binary mobile phase consisted of buffer ammonium formate/formic acid $10 \mathrm{mM} \mathrm{pH} 5.65$ (A) and acetonitrile (B) delivered at $0.3 \mathrm{~mL} \mathrm{~min}{ }^{-1}$; melatonin was eluted according to the following linear gradient: $A: B(70: 30 \mathrm{v} / \mathrm{v})$ for $6 \mathrm{~min}$, then $A$ : $B(0: 100 \mathrm{v} / \mathrm{v})$ over $11 \mathrm{~min}$. A return to the initial condition was accomplished in $5 \mathrm{~min}$ and held for additional $8 \mathrm{~min}$ to achieve column stabilization before next run (total run time $30 \mathrm{~min}$ ).

The mass spectrometer was an LCQ DECA XP Plus (Thermo Finnigan, San Josè, USA) Ion Trap mass spectrometer equipped with an ESI source and controlled by Xcalibur 1.3 software (Thermo Finnigan, San Josè, USA). To optimize the ESI source, flow injection analyses (FIA) with melatonin standard solution $\left(5 \mu \mathrm{g} \mathrm{mL}^{-1}\right)$ at different nebulizer and dryer gas flow and temperature were tested. The optimized parameters resulted the follow: source voltage $5 \mathrm{kV}$, capillary voltage $13 \mathrm{~V}$, sheath gas flow $\left(\mathrm{N}_{2}\right) 50$ arbitrary unit at $350{ }^{\circ} \mathrm{C}$. Data were acquired in positive MS total ion scan (mass scan range $m / z$ 100-2000) mode and in positive MS/MS mode. The normalized condition energy (nce \%) was optimized for the melatonin precursor ion selected $\mathrm{m} / \mathrm{z} 233$ at $30 \%$.

LC-ESI-MS/MS in single reaction monitoring (SRM) modality was applied to the selected precursor ion, following the condition set during the infusion analysis.

The parent/daughter ion transitions $\mathrm{m} / \mathrm{z} 233 \rightarrow 216$ and $\mathrm{m} / \mathrm{z} 233 \rightarrow 174$ were selected for the identification and quantification of melatonin. Concentration of melatonin was calculated by means of external calibration curve covering the range between 1.0 and $100.0 \mathrm{ng} \mathrm{mL}^{-1}$

\section{Results and discussion}

The aim of this study was to develop a method to quantify melatonin in different hemp (Cannabis sativa L.) varieties and organs. A simple methanol extraction from vegetal matrices with SPE clean-up protocol was set up, followed by the LC-ESI-MS/MS method where the proper selection of the chromatographic conditions (column, mobile phase) and the acquisition mode (MS/ MS) prevent matrix interferences.

The validated method was applied to analyse aerial parts and seeds of different hemp varieties belonging to fiber-type or drug-type chemotypes.

\subsection{Development of LC-MS/MS method}

To obtain MS-based information, direct flow injection experiments of reference compounds were initially performed, injecting standard methanolic solutions of melatonin into the ESI source with a syringe pump at a flow rate of $5.0 \mu \mathrm{min}^{-1}$. The ESI-MS full scan spectra of the melatonin were acquired over a $\mathrm{m} / \mathrm{z}$ range of $10-1000$ amu in positive polarity. Positive mass spectra of melatonin showed the main peak at $\mathrm{m} / \mathrm{z} 233$ corresponding to the pseudomolecular ion [M+H] ${ }^{+}$(Fig. 2a). ESI-MS/ MS spectra were performed to optimize the SRM assay. The pseudomolecular ion $[\mathrm{M}+\mathrm{H}]^{+}$at $m / z 233$, used as the precursor ion, generated the product ions at $m / z 174$ and 216 in the ESI-MS/MS spectra (Fig. 2b). The major fragment ion (base peak) at $m / z 174$ corresponded to the direct loss of a $\mathrm{NH}_{2} \mathrm{COCH}_{3}$ molecule $(-59 \mathrm{Da})$ from the pseudomolecular ion $[\mathrm{M}+\mathrm{H}]^{+}$. The minor fragment ion at $m / z 216$ corresponded to the loss of a $\mathrm{NH}_{3}$ molecule ( $-17 \mathrm{Da}$ ) from $\mathrm{m} / \mathrm{z} 233$, following the rearrangement of the pseudomolecular ion [35]. Thus, the SRM transitions $\mathrm{m} / \mathrm{z} 233 \rightarrow 216$ and $\mathrm{m} / \mathrm{z} 233 \rightarrow 174$ were selected for the identification and quantification of melatonin.

The LC_C18 column using acetonitrile-buffer ammonium formate/formic acid system was effective for the analysis of samples containing melatonin. Different mobile phase proportions $(60: 40,65: 35,70: 30 \mathrm{v} / \mathrm{v})$ were also tested and evaluated. Finally, the binary solvent system consisting of acetonitrile-gradient elution was effective for the analysis of melatonin in hemp products. The conditions were chosen to obtain the best separation of melatonin at retention time (Rt) $3.80 \mathrm{~min}$ as reported in Fig. 4 a.

\subsection{Analytical method validation}

The method was validated according to the guidelines of the International Conference on Harmonization $(\mathrm{ICH}$, Q2R1) by determining linearity, limit of detection (LOD), limit of quantitation (LOQ), precision, accuracy and solution stability. 


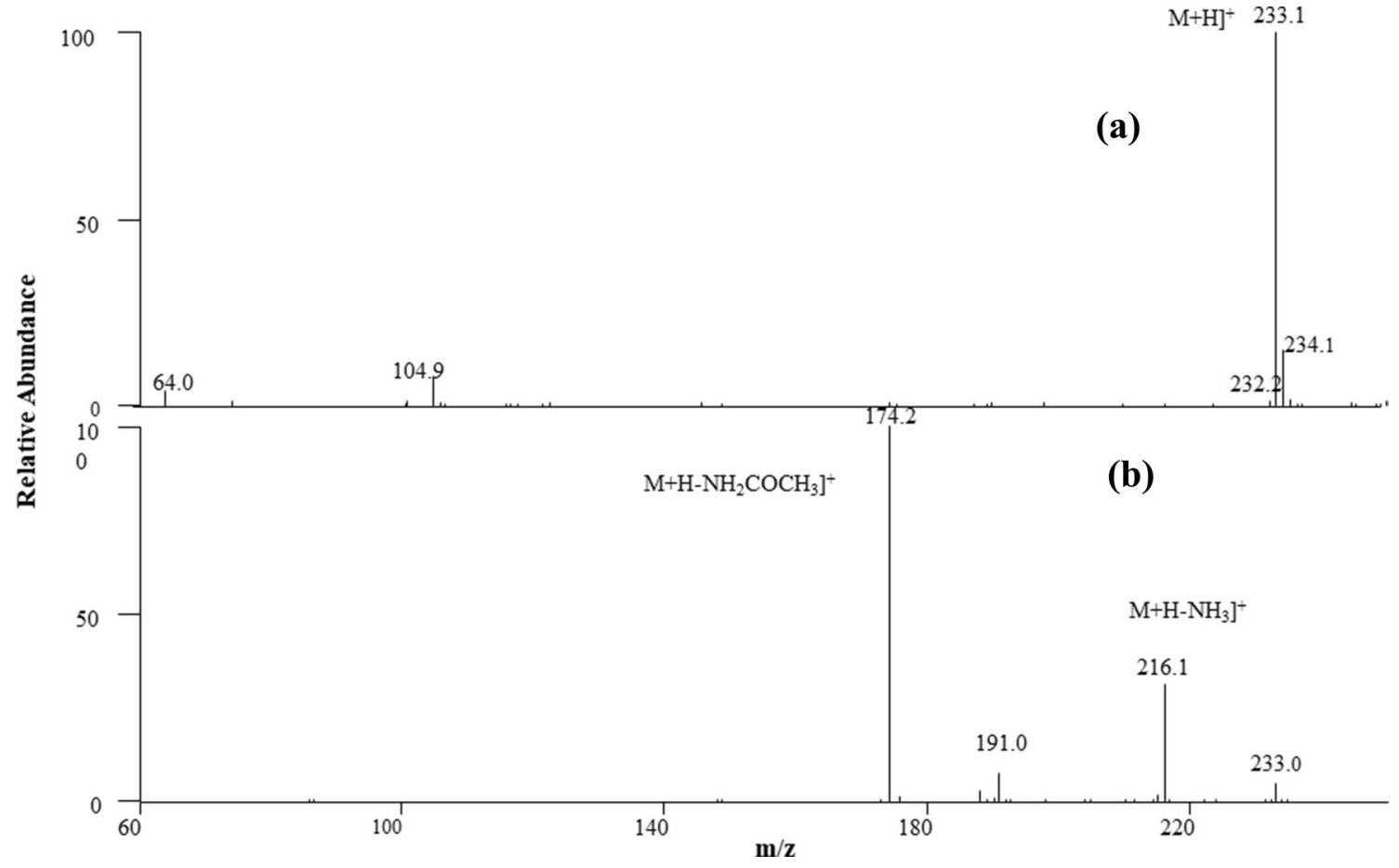

Fig. 2 (+) ESI-MS spectrum of melatonin (a); (+) ESI-MS/MS product ion mass spectrum of the pseudomolecular ion $[\mathrm{M}+\mathrm{H}]^{+}$at $m / z 233(\mathbf{b})$

\subsubsection{Linearity, LOD and LOQ}

The stability over the time of melatonin standard solutions and of extracted samples were evaluated by LC-MS/ MS analysis of the same sample stored at $4 \circ \mathrm{C}$ and weekly performed. A RSD below $6 \%$ was obtained confirming the stability.

Linearity of the method was evaluated at five concentration levels $\left(1.0,10.0,20.0,50.0,100.0 \mathrm{ng} \mathrm{mL}^{-1}\right)$ for melatonin diluting the standard stock solutions. The calibration curve was obtained by analyzing in triplicate each of these solutions. The analytical curve was expressed by mathematical model of the type $y=a x+b$, where $y$ is the analytical response, $x$ is the concentration of analyte in $\mathrm{ng} \mathrm{mL}^{-1}$, $a$ the slope of the curve and $b$ the intercept. Calculations were performed on the peak areas and the calibration curve equation and the R-square or coefficient of determination were determined. The LOD was first calculated from three replicate injections at the lowest detectable concentration level, via the formula: $\mathrm{LOD}(\mathrm{ng} / \mathrm{mL})=3 \times \mathrm{RSD}$ $x$ concentration. From this calculated value, the LOD was determined experimentally on signal to noise ratio by establishing the minimum concentration at which the analyte was characterized to have at least a signal to noise ratio $(\mathrm{S} / \mathrm{N})$ 3:1. For melatonin the LOD was determined by injecting lower concentration solutions of melatonin and visualizing the $\mathrm{S} / \mathrm{N}$ ratio of the peak in the corresponding chromatograms.

The estimated LOQ was calculated from three replicate injections, via the formula: $\operatorname{LOD}\left(\mathrm{ng} \mathrm{mL}^{-1}\right)=10 \times \mathrm{RSD}$ $x$ concentration. From this calculated value, the LOQ was determined experimentally on signal to noise ratio by establishing the minimum concentration at which the analyte was characterized to have at least a signal to noise ratio $(\mathrm{S} / \mathrm{N})$ 10:1. For melatonin the $L O Q$ was determined by injecting lower concentration solutions of melatonin and visualizing the $\mathrm{S} / \mathrm{N}$ ratio of the peak in the corresponding chromatograms.

The calibration curve showed a good linearity $(y=77356 x+35351)$ in the range of $1.0-100.0 \mathrm{ng} \mathrm{mL}^{-1}$ with the coefficient of determination $R^{2}=0.9984$ (Fig. 3). The LOD was found to be $0.10 \mathrm{ng} \mathrm{mL}^{-1}$ and LOQ found to be $0.35 \mathrm{ng} \mathrm{mL}^{-1}$

\subsubsection{Precision and recovery}

Intra-day and inter-day reference compound variations were chosen to determine the precision of the developed method. The intra-day and the inter-day precision were investigated using two sample solutions formulated at two different concentrations of 10 and $20 \mathrm{ng} \mathrm{mL}^{-1}$ of melatonin standard. For the intraday repeatability each solution was analyzed with six 


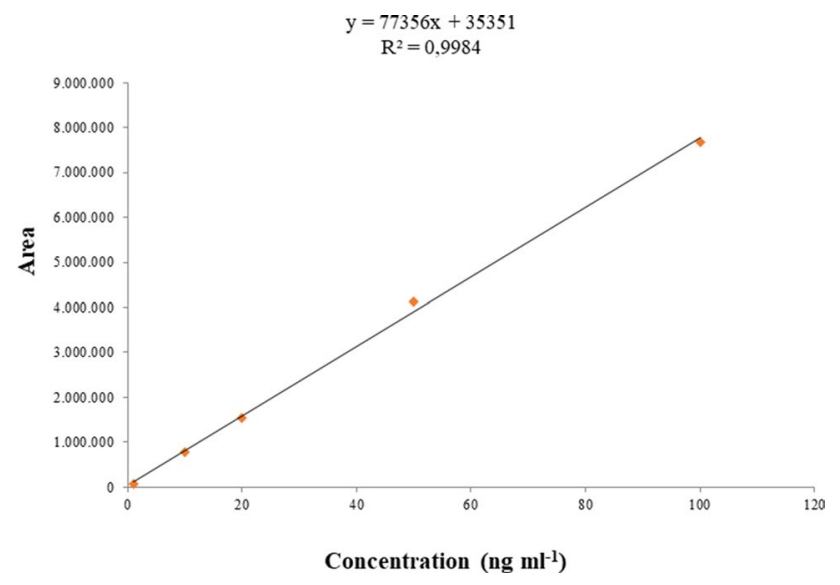

Fig. 3 Calibration curve of melatonin

replicates performed during the same day and the peak areas obtained were used to calculate the means and the RSD values $(n=6)$. For the inter-day precision, each sample solution was checked on three different days with three replicates performed each day, and the means and RSD were calculated from peak areas of the reference compound $(n=9)$. Good results were obtained for method precision with the RSD values for intra-day repeatability and inter-day precision lower than 3.1 and $3.5 \%$, respectively (Table 1 ).

The accuracy of the method was examined by the standard addition method for recovery study at three concentration levels. Hemp samples of Ermo aerial parts and seeds were spiked with three different amounts of melatonin standard to add a final concentration of 100 and 150 and $200 \%$ of the initial melatonin amount. The spiked samples were extracted with methanol and SPE following the same procedures as previously described for the samples. Then the obtained spiked extracts were analyzed in triplicate using the LC-MS/MS method described. Quantitative amounts were calculated using the melatonin calibration curves and recoveries were calculated on the basis of AOAC methods [36]. Satisfactory percentage recoveries were obtained for the three levels, ranging from 87 to $96 \%$, with a mean recovery of $91 \%$ for aerial parts and ranging from 82 to $91 \%$, with a mean recovery of $87 \%$ for seeds samples (Table 2 ).

Table 1 Precision data for melatonin

\begin{tabular}{lrllll}
\hline $\begin{array}{l}\text { Analyte } \\
\text { melatonin } \\
\left(\mathrm{ng} \mathrm{mL} \mathrm{mL}^{-1}\right)\end{array}$ & \multicolumn{2}{l}{ Intraday precision } & & \multicolumn{2}{l}{ Interday precision } \\
\cline { 2 - 3 } \cline { 5 - 6 } & Mean \pm SD & $\begin{array}{l}\text { RSD } \% \\
(\mathrm{n}=6)\end{array}$ & & Mean \pm SD & RSD \% $(n=9)$ \\
\hline 10 & $9.41 \pm 0.26$ & 2.77 & & $9.24 \pm 0.22$ & 2.35 \\
20 & $18.81 \pm 0.58$ & 3.07 & & $17.13 \pm 0.60$ & 3.50 \\
\hline
\end{tabular}

Mean $=$ mean of calculated concentration $\left(\mathrm{ng} \mathrm{mL}^{-1}\right)$
Table 2 Recovery data from Cannabis sativa L. aerial parts and seeds extracts spiked with different amounts of melatonin

\begin{tabular}{llll}
\hline & $\begin{array}{l}\text { Original mela- } \\
\text { tonin } \mathrm{ng} 3.00 \mathrm{~g}^{-1}\end{array}$ & Spiked \% & Recovery \% (RSD \%) \\
\hline Aerial parts & 9.24 & 100 & $87(3.01)$ \\
& & 150 & $89(3.05)$ \\
& & 200 & $96(2.84)$ \\
Seeds & 91.20 & 100 & $82(2.55)$ \\
& & 150 & $91(3.41)$ \\
& & 200 & $88(3.20)$ \\
\hline
\end{tabular}

\subsection{Quantitative analysis of samples}

The validated method was applied to the quantification of melatonin in aerial parts and seeds of hemp varieties samples belonging to fiber-type or drug-type chemotypes.

In Fig. $4 \mathrm{~b}$ the LC-MS/MS chromatogram of hemp aerial parts sample (CBD chemotype) is reported.

In Table 3 the melatonin content of the aerial partsleaves and flower heads - of hemp varieties harvested at the maturity phase are reported. Melatonin concentrations of aerial parts ranged from 1.16 to $4.85 \mathrm{ng} \mathrm{g}^{-1}$-medium value of a $3.10 \mathrm{ng} \mathrm{g}^{-1}-$, with the CBD chemotype presenting the highest melatonin concentration $\left(4.85 \mathrm{ng} \mathrm{g}^{-1}\right)$ and THC chemotype showing the lowest one $\left(1.16 \mathrm{ng} \mathrm{g}^{-1}\right)$. Moderate variability is observed when comparing the data from the two harvests, 2012 and 2013, of CBG chemotypeCarma variety: climatic conditions could have a clear effect on melatonin concentration since the analyzed samples were grown in similar condition each harvest.

The melatonin content of aerial parts of hemp varieties under study is within the range of plants like Olea europaea L. and Laurus nobilis L. [17, 28].

In Fig. 4c the LC-MS/MS chromatogram of hemp seeds sample (Ermo variety) is reported. Table 3 shows the melatonin concentration determined in hemp seeds and. Melatonin concentrations in seeds ranged from 13.43 to $30.40 \mathrm{ng} \mathrm{g}^{-1}$ (mean value: $19.74 \mathrm{ng} \mathrm{g}^{-1}$ ), with a variety devoid of cannabinoids showing the highest melatonin concentration $\left(30.40 \mathrm{ng} \mathrm{g}^{-1}\right)$ and CBD chemotype showing the lowest melatonin concentration $\left(13.43 \mathrm{ng} \mathrm{g}^{-1}\right)$. Seeds contain the highest amount of melatonin in hemp. The high amount of melatonin detected in seeds is in accord with its essential function in protecting germ and reproductive tissues of plants $[17,19]$ and is within the content of plants like Lupinus albus L. [20, 23].

No correlation was found between the melatonin levels detected in aerial parts and seeds in each hemp variety and the concentration of specific cannabinoids. Anyway he highest level of melatonin detected in the hemp seeds of the variety [37] devoid of these compounds, 
Fig. 4 LC-ESI-MS/MS chromatograms of melatonin standard solution (a) aerial parts extract (b) seeds extract (c)
Table 3 Melatonin mean content $\left(\mathrm{ng} \mathrm{g}^{-1}\right)$ in different organs of hemp varieties harvested in 2013 and 2012

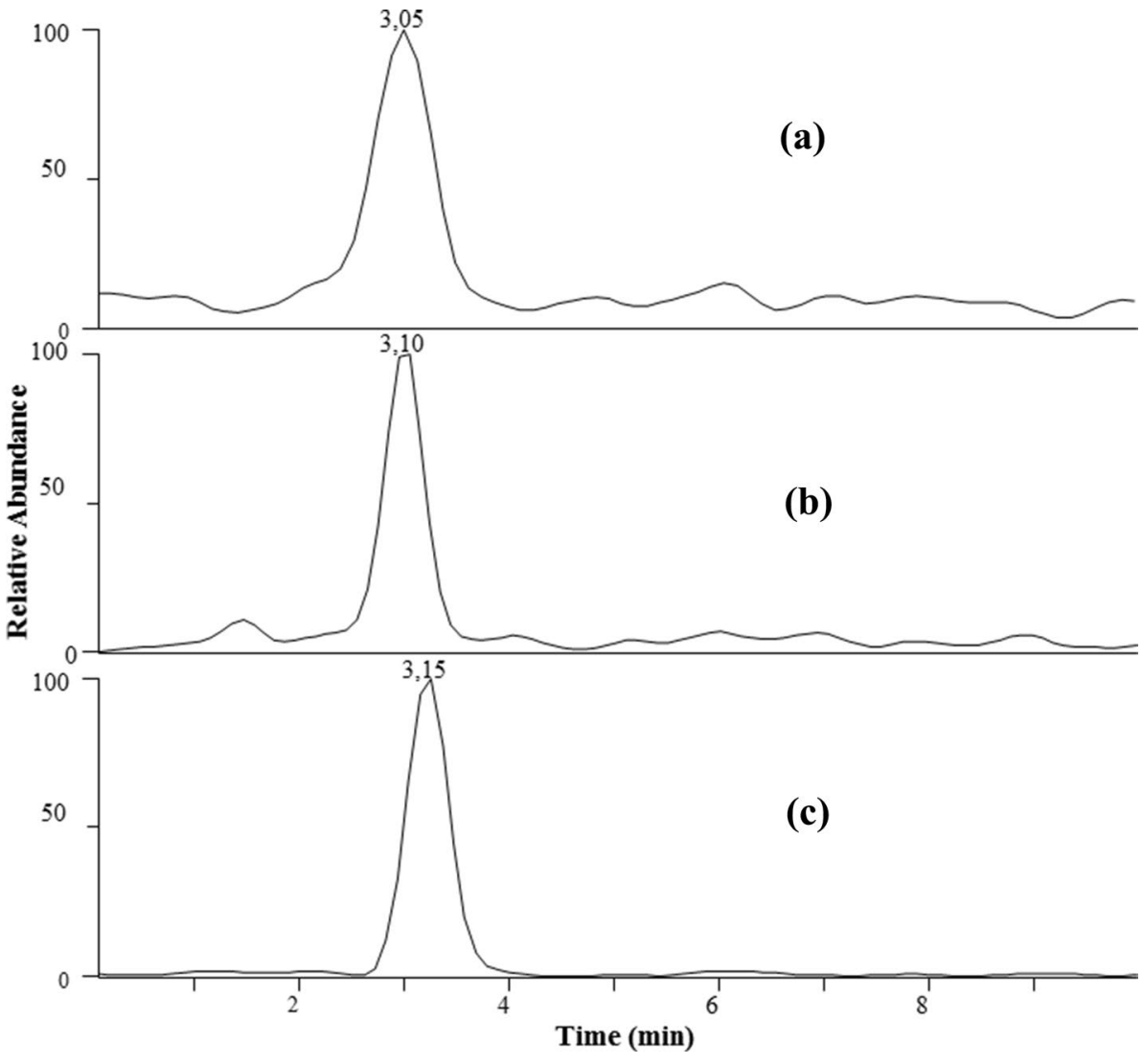

\begin{tabular}{llll}
\hline $\begin{array}{l}\text { Cannabis sativa L. } \\
\text { varieties }\end{array}$ & Chemotype & $\begin{array}{l}\text { Melatonin in leaves and } \\
\text { flower heads } \\
\text { Mean } \pm \text { SD }\end{array}$ & $\begin{array}{l}\text { Melatonin in seeds } \\
\text { Mean } \pm \text { SD }\end{array}$ \\
\hline Ermes & CBD & $4.85 \pm 0.16^{a}$ & $17.91 \pm 0.47$ \\
Carma & CBG & $3.77 \pm 0.05^{a}$ & $14.66 \pm 0.74$ \\
Carma & CBG & $2.65 \pm 0.05^{b}$ & \\
Ermo & No cannabinoids & $3.08 \pm 0.05^{a}$ & $30.40 \pm 0.64$ \\
Thc & THC & $1.16 \pm 0.01^{a}$ & $22.30 \pm 0.03$ \\
Codimono & CBD & & $13.43 \pm 0.48$ \\
\hline
\end{tabular}

${ }^{\mathrm{a}}$ Harvested in 2013

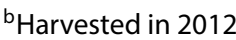

suggest that this could be a valuable food suitable to produce positive effect in relation to modulate the sleep and physiological balance of related to wellness states.

\section{Compliance with ethical standards}

Conflict of interest On behalf of all authors, the corresponding author states that there is no conflict of interest.

\section{References}

1. Carrillo-Vico A, Guerrero JA, Lardone PJ, Reiter RJ (2005) A review of the multiple actions of melatonin on the immune system. Endocrine 27:189-200

2. Axelrod J (1974) The pineal gland: a neurochemical transducer. Science 184:1341-1348

3. Pandi-Perumal SR, Srinivasan V, Maestroni GJM, Cardinali DP, Poeggeler B, Hardeland R (2006) Melatonin, nature's most versatile biological signal? FEBS J 273:2813-2838

4. Slominski RM, Reiter RJ, Schlabritz-Loutsevitch N, Ostrom RS, Slominski AT (2012) Melatonin membrane receptors in 
peripheral tissues: distribution and functions. Mol Cell Endocrinol 352:152-166

5. Maestroni GJM, Conti A, Pierpaoli W (1986) Role of the pineal gland in immunity: circadian synthesis and realize of melatonin modulates antibody response and antagonizes the immunosuppressive effect of cortisone. J Neuroimmunol 13:19-30

6. McMullan CJ, Schernhammer ES, Rimm EB, Hu FB, Forman JP (2014) Melatonin secretion and the incidence of type 2 diabetes. NIH Public Access 309:1388-1396

7. Ho Siah KT, Kong Min Wong R, Yu Ho K (2014) Melatonin for the treatment of irritable bowel syndrome. World J Gastroenterol 20:2492-2498

8. Chojnacki C, Walecka-Kapica E, Lokiec K, Pawlowicz M, Winczyk K, Chojnacki J, Klupinska G (2013) Influence of melatonin on symptoms of irritable bowel syndrome in postmenopausal women. Endokrynol Pol 64:114-120

9. Saha L, Malhotra S, Rana S, Bhasin D, Pandhi P (2007) A preliminary study of melatonin in irritable bowel syndrome. J Clin Gastroenterol 41:29-32

10. Kanishi Y, Kobayashi Y, Noda S, Ishizuka B, Saito K (2000) Differential growth inhibitory effect of melatonin on two endometrial cancer cell lines. J Pineal Res 28:227-233

11. Cutando A, Lopez-Valverde A, De Vicente J, Lòpez Gimenez J, Alias Carcial, Gomez de Diego R (2014) Action of melatonin on squamous cell carcinoma and other tumors of the oral cavity. Oncol Lett 7:923-926

12. Dubbels R, Reiter RJ, Klenke E, Goebel A, Schnakemberg E, Ehlers C, Schiwara HW, Schloot W (1995) Melatonin in edible plants identified by radioimmunoassay and by high performance liquid chromatography-mass spectrometry. J Pineal Res 18:28-31

13. Hattori A, Migitaka $H$, Ligo $M$, Itoh $M$, Yamamoto $K$, OhtaniKaneko R, Hara M, Suzuki T, Reiter RJ (1995) Identification of melatonin in plants and its effects on plasma melatonin levels and binding to melatonin receptors in vertebrates. Biochem Mol Biol Int 35:627-634

14. Paredes SD, Korkmaz A, Manchaster LC, Tan DX, Reiter RJ (2009) Phytomelatonine: a review. J Exp Bot 60:57-69

15. Posmyk MM, Janas KM (2009) Melatonin in plants. Acta Physiol Planta 31:1-11

16. Arnao MB, Hernández-Ruiz J (2009) Chemical stress by different agents affects the melatonin content of bareley roots. J Pineal Res 46:295-299

17. Arnao MB (2014) Phytomelatonin: discovery, content and role in plants. Adv Bot ID 815769

18. Shi H, Reiter RJ, Tan DX, Chan Z (2015) Indole-3-acetic acid inducible 17 positively modulates natural leaf senescence through melatonin-mediated pathway in Arabidopsis. J Pineal Res 58:26-33

19. Manchester LC, Tan DX, Reiter RJ, Park W, Monis K, Qi W (2000) High levels of melatonin in the seeds of edible plants. Possible function in germ tissue protection. Life Sci 67:3023-3029

20. Hernández-Ruiz J, Arnao MB (2008) Distribution of melatonin in different zones of lupin and barley plants at different ages in the presence and absence of light. J Agric Food Chem 56:10567-10573

21. Zhang N, Sun Q, Zhang H, Cao Y, Weeda S, Ren S, Guo Y (2015) Roles of melatonin in abiotic stress resistance in plants. J Exp Bot 66:647-656
22. Zhang N, Zhao B, Zhang H, Weeda S, Yang C, Yang Z, Ren S, Guo $Y(2013)$ Melatonin promotes water-stress tolerance, lateral root formation and seed germination in cucumber (Cucumis sativus L.). J Pineal Res 54:15-23

23. Kolář J, Macháčková I (2005) Melatonin in higher plants: occurrence and possible functions. J Pineal Res 39:333-341

24. Murch SJ, Simmons CB, Saxena PK (1997) Melatonin in feverfew and other medicinal plants. The Lancet 350:1598-1599

25. Arnao MB, Hernández-Ruiz J (2009) Assessment of different sample processing procedures applied to the determination of melatonin in plants. Phytochem Anal 20:14-18

26. Burkhardt S, Tan DX, Manchester LC, Hardeland R, Reiter RJ (2001) Detection and quantification of the antioxidant melatonin in montmorency and balaton tart cherries (Prunus cerasus). J Agric Food Chem 49:4898-4902

27. Feng $X$, Wang $M$, Zhao $Y$, Han $P$, Dai $Y$ (2014) Melatonin from different fruit sources, functional roles and analytical methods. Trends Food Sci Technol 37:21-31

28. De la Puerta C, Carrascosa-Salmoral MP, García-Luna PP, Lardone PJ, Herrera JL, Fernández-Montesinos R, Guerrrero JM, Pozo D (2007) Melatonin is a phytochemical in olive oil. Food Chem 104:609-612

29. Hanuš LO, Meyer SM, Muñoz E, Taglialatela-Scafati O, Appendino GB (2016) Phytocannabinoids: a unified critical inventory. Nat Prod Rep 33:1357-1392

30. Mediavilla V, Steinemann S (1997) Essential oil of Cannabis sativa L. strains. J Int Hemp Assoc 4:80-82

31. ElSohly MA, Slade D (2005) Chemical constituents of marijuana: the complex mixture of natural cannabinoids. Life Sci 78:539-548

32. Radwan MM, Elsohly MA, Slade D, Ahmed SA, Wilson L, El-Alfy AT, Khan IA, Ross SA (2008) Non cannabinoids constituents from a high potency Cannabis sativa variety. Phytochemistry 69:2627-2633

33. Flores-Sanchez IJ, Verpoorte R (2008) Secondary metabolism in cannabis. Phytochem Rev 7:615-639

34. Cao Murch SJ, O'Brien R, Saxena PK (2006) Rapid method for accurate analysis of melatonin, serotonin and auxin in plant samples using liquid chromatography tandem mass spectrometry. J Chromatogr A 1134:333-337

35. Gomez FJV, Hernández IG, Martinez LD, Silva MF, Cerutti S (2013) Analytical tools for elucidating the biological role of melatonin in plants by LC-MS/MS. Electrophoresis 34:1749-1756

36. Horwitz W. Recovery studies (2000) Official method of analysis of the Association of Official Analytical Chemists International, 17th edn, Byrd Richmond

37. Werz O, Seegers J, Schaible AM, Weinigel C, Barz D, Koeberle A, Allegrone G, Pollastro F, Zampieri L, Grassi G, Appendino GB (2014) Cannflavins from hemp sprouts, a novel cannabinoidfree hemp food product, target microsomal prostaglandin E2 synthase-1 and 5-lipoxygenase. PharmaNutrition 2:53-60

Publisher's Note Springer Nature remains neutral with regard to jurisdictional claims in published maps and institutional affiliations. 